\title{
The efficacy of acibenzolar-S-methyl (ASM) in inducing resistance against Fusarium graminearum sensu stricto in wheat (Triticum aestivum L.)
}

\author{
Sinegugu Precious N. Shude, Nokwazi C. Mbili \& Kwasi S. Yobo*
}

Discipline of Plant Pathology, School of Agricultural, Earth and Environmental Sciences, University of KwaZulu-Natal, Private Bag X01, Scottsville, Pietermaritzburg, 3209, Republic of South Africa

^Email: Yobok@ukzn.ac.za

\section{OPEN ACCESS}

\section{ARTICLE HISTORY}

Received: 29 July 2021

Accepted: 29 October 2021

Available online

Version 1.0 (Early Access): 07 December 2021 Version $2.0: 01$ January 2022

\section{Check for updates}

\section{Additional information}

Peer review: Publisher thanks Sectional Editor and the other anonymous reviewers for their contribution to the peer review of this work.

Reprints \& permissions information is available at https://horizonepublishing.com/ journals/index.php/PST/open_access_policy

Publisher's Note: Horizon e-Publishing Group remains neutral with regard to jurisdictional claims in published maps and institutional affiliations.

Indexing: Plant Science Today, published by Horizon e-Publishing Group, is covered by Scopus, Web of Science, BIOSIS Previews, Clarivate Analytics, etc. See https:// horizonepublishing.com/journals/index.php/ PST/indexing_abstracting

Copyright: $($ The Author(s). This is an openaccess article distributed under the terms of the Creative Commons Attribution License, which permits unrestricted use, distribution and reproduction in any medium, provided the original author and source are credited (https://creativecommons.org/licenses/ by/4.0/)

\section{CITE THIS ARTICLE}

Shude S P N, Mbili N C, Yobo KS. The efficacy of acibenzolar-S-methyl (ASM) in inducing resistance against Fusarium graminearum sensu stricto in wheat (Triticum aestivum L.). Plant Science Today. 2022;9(1):183-190. https://doi.org/10.14719/pst.1419

\begin{abstract}
Four ASM (acibenzolar-S-methyl) concentrations were applied on wheat plants at different growth stages prior to inoculation with $1 \times 10^{5}$ conidia $/ \mathrm{ml}$ of Fusarium graminearum. Thereafter, disease severity was monitored and recorded over time. All ASM concentrations reduced disease severity compared to the control. The best treatment, providing the lowest Area Under the Disease Progress Curve (AUDPC) units, high average Hundred Seed Weight (HSW) and reduced average Percentage Seed Infection (PSI), was $0.075 \mathrm{~g} / \mathrm{L} \mathrm{ASM}$ applied at anthesis. A weak but significant positive correlation was observed between AUDPC and PSI $(r=0.33 ; p=0.0001)$. However, a moderate and weak negative correlation was observed between AUDPC and HSW $(r=-0.41 ; p<0.0001)$ and HSW and PSI $(r=-0.18 ; p=0.04)$ respectively. Higher ASM concentrations were more effective when applied at anthesis and lower concentrations at late boot. Moreover, repeated applications (applied at both late boot and anthesis) did not improve disease reduction. A disease reduction and deoxynivalenol (DON) reduction of up to $28.97 \%$ ( $0.075 \mathrm{~g} / \mathrm{L}$ ASM applied at anthesis) and $18.79 \%$ (0.0375 g/L ASM applied at anthesis) was observed. However, DON and zearalenone (ZEA) reduction did not always correspond with disease severity reduction of tested treatments. This accentuates the importance of the development of integrated control strategies for the improved and effective management of Fusarium head blight (FHB) in wheat.
\end{abstract}

\section{Keywords}

Fusarium Head Blight, Cereal, Deoxynivalenol, Mycotoxins, Induced Systemic Resistance, Disease Control

\section{Introduction}

Fusarium head blight (FHB) is an economically important disease of cereal crops worldwide causing yield and quality losses and the contamination of grains with mycotoxins, such as deoxynivalenol (DON) and zearalenone (ZEA) $(1,2)$. These mycotoxins can have deleterious effects on both human and animal health $(1,2)$. FHB is caused by a Fusarium-species complex consisting of up to 17 species, amongst which F. graminearum sensu stricto [teleomorph: Gibberella zeae (Schwein.) Petch] and F. culmorum (FC) (W.G. Smith) Saccardo are the most virulent species worldwide (1, 3-5).

Previous efforts in the control of FHB have focused mainly on chemical control, the use of biological control agents (BCAs) and resistance breeding (1). Regardless of previously reported efficacies, the inconsistency and lack of durability of some BCAs, and the residue and resistance develop- 
ment concerns associated with fungicides are major limitations in the development of FHB control strategies (1). Some researchers believe that improving host genetic resistance could provide more meaningful, durable and consistent protection against FHB and its mainly produced mycotoxin, DON (6-9).

FHB and DON resistance in small grain crops is complex and quantitatively inherited and can be achieved by the expression of at least two of the five resistance types, namely: (i), resistance to initial infection; (ii), resistance to spread in infected tissue; (iii), resistance to kernel infection; (iv), tolerance; and (v), resistance to accumulation of toxins $(1,9)$. In recent years, the mapping of quantitative trait loci (QTL), such as Fhb1 derived from the Chinese wheat cultivar 'Sumai 3', has been researched extensively as a potential source of FHB resistance (1). Due to FHB resistance being acquired quantitatively, resistance breeding programmes have been slow resulting in only a few moderately resistant cultivars being produced thus far ( 1 , 9).

The over-expression of some resistance genes such as those incited by jasmonic acid (JA), ethylene (ET) and salicylic acid (SA) have been reported to improve FHB resistance $(1,10)$. This is by the activation of the host defence mechanisms resulting in enhanced induced systemic resistance (ISR) (signalled by JA and ET) and systemic acquired resistance (SAR) (signalled by SA) which differ according to the nature of the elicitor and the regulatory pathways involved $(10,11)$.

Moreover, previous research has reported on JA signalling being more important in the control of necrotrophic and hemi-biotrophic pathogens (such as F. graminearum) compared to SA signalling $(12,13)$. However, it has also been reported that these signalling pathways are complex and may act cumulatively in resistance development $(10-12,14)$. That is, SA and JA signalling pathways may not interfere with one another but work individually in the plant to result in a collective improvement of wheat resistance $(10,11)$.

SAR is characterised by the activation and accumulation of SA and the production of pathogenesis-related (PR) genes and thus protecting plants from further infection $(11,15)$. In plant disease control, SAR is the most studied compared to ISR since it provides specific and longlasting resistance against pathogens $(15,16)$. SAR can be triggered in plants by response to local infection and by the application of chemical inducers such as SA $(10,15$, 17). According to one report (15), spraying wheat plants with benzo-(1, 2, 3)-thiadiazole-7-carbothioic acid Smethyl ester (BTH), a synthetic functional analogue of SA, at early developmental stages resulted in induced resistance against Erysiphe graminis f. sp. tritici É.J. Marchal, Puccinia recondita Roberge ex Desm. and Septoria spp.

The inoculation of wheat plants with BTH resulted in an enhanced expression of the PR1 gene which activates SA signalling and promotes wheat resistance to Fusarium infection (16). This suggested that SA signalling was triggered thus activating SAR in the wheat plants and improv- ing resistance to F. graminearum $(10,16)$. Moreover, further study reported that the FHB resistance and BTH sensitivity of the AtNPR1-expressed in wheat was comparable to that of the resistant 'Sumai 3' cultivar (16).

Results revealed that SA signalling was induced early (12 hrs) after the inoculation of wheat spikes with $F$. graminearum whereas JA signalling was induced later (48 hrs) (14). This led to a possible conclusion that SA signalling was responsible for basal resistance to FHB whereas JA signalling reduced further infection by the pathogen (14). This agrees with other studies where a cumulative effect between JA and SA signalling in the control of FHB was reported $(10,12)$. However, other research has reported on SA and BTH being ineffective in inducing SA signalling in wheat plants (13). Therefore, more research into understanding the complexity and efficacy of these elicitors in SAR induction and FHB resistance in wheat plants is crucial. Nonetheless, in the absence of effective FHB control strategies, the use of resistance inducers could provide an alternative control strategy to reduce FHB severity in wheat.

Acibenzolar-S-methyl (ASM), a derivative of BTH, is currently registered as a resistance inducer for tomatoes (Solanum lycopersicum L.) and mangoes (Mangifera indica L.). Small doses of ASM activate resistance in many crops against a wide range of diseases (18). The resistance induced by ASM in monocotyledonous plants is more durable compared to that induced in dicotyledonous plants (18). Previous studies have been conducted on the efficacy of ASM to induce resistance in wheat plants against various diseases $(11,19)$. However, there is limited research on the efficacy of ASM against FHB in wheat. Since the use of fungicides is accompanied by cost, residue and pathogen resistance development concerns, the use of small doses of ASM could mitigate these concerns and possibly provide effective $\mathrm{FHB}$ reduction.

In this study, the efficacy of ASM application in reducing FHB disease severity and mycotoxin contamination upon $F$. graminearum infection was investigated. The effectiveness of ASM was measured using the following parameters: (i) disease severity over time, (ii) hundred seed weight (HSW), (iii) percentage seed infection (PSI) and (iv) mycotoxin (DON and ZEA) concentration in harvested grain.

\section{Materials and Methods \\ Planting and experimental design}

Sixty-five planting pots of $25 \mathrm{~cm}$ diameter were filled up to $90 \%$ capacity with composted pine bark potting medium. Thereafter, five seeds were sown at even spacing in each pot which constituted an experimental unit. The trial consisted of 13 treatments (Table 1 ) with five replicates each. A 4 × 3 factorial design (four ASM concentrations and three inoculation periods/time) and a control was used for this experiment (Table 1). The pots were placed in a growing area with insect netting (approximately 15\% shading) and a drip irrigation system was used where each pot received 
Table 1. The acibenzolar-S-methyl (ASM) concentrations and application times applied on wheat plants in vivo.

\begin{tabular}{cccl}
\hline $\begin{array}{c}\text { Treat- } \\
\text { ment } \\
\text { number }\end{array}$ & $\begin{array}{c}\text { ASM concen-ASM concen- } \\
\text { tration } \\
(\%)\end{array}$ & $\begin{array}{c}\text { ASM application time(s) } \\
\text { tration } \\
(\mathbf{g} / \mathrm{L})\end{array}$ & \multicolumn{1}{c}{ AS } \\
\hline 1 & 25 & 0.019 & Late boot stage $(\mathrm{BBCH} 45)$ \\
2 & 25 & 0.019 & Anthesis (BBCH 61) \\
3 & 25 & 0.019 & Late boot stage and anthesis \\
4 & 50 & 0.038 & Late boot stage (BBCH 45) \\
5 & 50 & 0.038 & Anthesis (BBCH 61) \\
6 & 50 & 0.038 & Late boot stage and anthesis \\
7 & 75 & 0.056 & Late boot stage (BBCH 45) \\
8 & 75 & 0.056 & Anthesis (BBCH 61) \\
9 & 75 & 0.056 & Late boot stage and anthesis \\
10 & 100 & 0.075 & Late boot stage (BBCH 45) \\
11 & 100 & 0.075 & Anthesis (BBCH 61) \\
12 & 100 & 0.075 & Late boot stage and anthesis \\
13 & $0($ Control) & 0.000 & Anthesis (BBCH 61) \\
\hline
\end{tabular}

water for 2 mins four times a day. Osmocote Exact Mini 5-6 M 15-3.9-9.1 + 1.2 Mg + TE [supplied by Greenhouse products (Pvt) Ltd, Helderkruin, Republic of South Africa (RSA)], an ammonium based slow-release fertilizer, was applied in each pot at a rate of $2.5 \mathrm{~g} / \mathrm{L}$ of potting media.

\section{ASM and F. graminearum applications}

Five litres (5L) of tap water were poured in clean beakers and placed on a bench top in the laboratory for one hour to facilitate the release of excess chlorine. ASM granules (purchased from Syngenta (Pvt) Ltd, Halfway house, Johannesburg, RSA) were weighed out according to the assigned treatments and dissolved in $1 \mathrm{~L}$ of tap water each. This was repeated for all treatments resulting in four ASM concentrations and a negative control (tap water only, no ASM). For each treatment, the ASM solution was transferred into a clean and labelled $1 \mathrm{~L}$ polystyrene spray bottle. According to the ASM application specifications, the recommended dosage on tomato plants is $0.075 \mathrm{~g} / \mathrm{L}$. The treatments in this study were therefore derived from this recommended dosage. The resulting concentrations were: $0.075 \mathrm{~g} / \mathrm{L}(100 \%$, full strength), $0.0563 \mathrm{~g} / \mathrm{L}$ (75\%, three-quarter strength); $0.0375 \mathrm{~g} / \mathrm{L}(50 \%$, half strength) and $0.019 \mathrm{~g} / \mathrm{L}$ (25\%, quarter strength).

Using a fine mist nozzle, the plants were sprayed with the ASM solutions until run-off at three application times [late boot (BBCH 45) (20), anthesis (BBCH 61) (20) and late boot and anthesis]. The treatments were applied separately, away from other treatments, to prevent spray drift. This was repeated for all 13 treatments.

At anthesis, a F. graminearum conidia suspension was prepared using fully grown $F$. graminearum sensu stricto strain F20 cultures. This strain was obtained from a stock solution in the Discipline of Plant Pathology stock culture laboratory, University of KwaZulu-Natal, Pietermaritzburg, South Africa and was previously isolated from infected wheat heads in a wheat cultivation field. In each culture plate, $4 \mathrm{~mL}$ of sterile distilled water was poured and a flame -sterilized L-bent glass rod was used to dislodge the mycelia. The suspension was shaken briefly and sieved through a sterile cheesecloth to remove mycelia and agar debris. Using a haemocytometer, the conidia concentration was adjusted to $1 \times 10^{5}$ conidia/mL and the solution was transferred into a clean $1 \mathrm{~L}$ polystyrene spray bottle. For all treatments, wheat heads were sprayed with a fine mist of the F. graminearum strain F20 conidia suspension until run-off. For the late boot ASM treatments, F. graminearum was sprayed at anthesis. For the treatments where ASM was applied at anthesis, F. graminearum was sprayed 48 hrs after ASM applications. The wheat heads were covered with plastic bags for $24 \mathrm{hrs}$ to enhance disease development. Disease severity was measured using a visual scale (21) and disease ratings were recorded from first symptom appearance to complete infection of the control treatment.

Before harvesting, seed maturity was monitored by sampling wheat spikelets at random throughout the field to determine whether the grains were ready for harvest. When all the plants had fully matured and had a golden-brown appearance, the wheat heads were harvested per treatment replicate by cutting them off from the straws using a pair of scissors and were placed in appropriately labelled collection bags. The heads were dried in a ventilating oven set at $55^{\circ} \mathrm{C}$ for 4 days, where they were continuously monitored and repositioned every 2 days to prevent heat damage of the seeds. Thereafter, the wheat heads were threshed and the seeds were transferred into appropriately labelled envelopes. The trial was repeated once.

The hundred seed weight (HSW) and percentage seed infection (PSI) were determined per treatment replicate for the two experiments. For the PSI, the seeds were first surface sterilized by submerging them in $70 \%$ ethanol for 30 secs, followed by 30 secs in $2 \%$ sodium hypochlorite and then rinsed for $1 \mathrm{~min}$ in sterile distilled water. Thereafter, the seeds were air-dried under the laminar flow for 10 mins, cultured on freshly prepared PDA plates and incubated at $25^{\circ} \mathrm{C}$ for 4 days. Since each treatment had five replicates, each replicate had three plates of which each plate had 15 seeds. The experiment was repeated once resulting in 30 plates per treatment. The number of Fusariuminfected seeds per plate was recorded and used to calculate the PSI.

\section{Mycotoxin analysis}

The target mycotoxins were DON and ZEA since they are the most prevalent mycotoxins in $\mathrm{FHB}$ infections. The roQ ${ }^{\mathrm{TM}}$ QuEChERS kits KSO-8909 and KSO-9507 were used for sample extraction and dispersive Solid Phase Extraction (dSPE) respectively. These were purchased from Separations (Pvt) Ltd, Johannesburg, RSA. Mycotoxin extraction (22) was performed with modifications.

Wheat seeds from the two experiments were pooled according to treatments resulting in 13 samples for mycotoxin analysis. For each sample, the seeds were ground into fine powder using a Mikro-Feinmuhle-Cullati (MFC) plant grinder (22). A $5 \mathrm{~g}$ subsample was added into a $50 \mathrm{ml}$ roQ QuEChERS extraction tube along with the following reagents: Milli-Q water $(10 \mathrm{ml})$, acetonitrile with $5 \%$ formic acid $(10 \mathrm{ml})$ and the contents of the roQ QuEChERS extraction packet (KSO-8909) which consisted of $4.0 \mathrm{~g} \mathrm{MgSO}_{4}, 1.0 \mathrm{~g}$ 
$\mathrm{NaCl}, 1.0 \mathrm{~g}$ SCTD and $0.5 \mathrm{~g}$ SCDS (22).

The tube was shaken for $1 \mathrm{~min}$ by hand and then centrifuged at $4000 \mathrm{rpm}(3000 \mathrm{~g})$ for 5 mins (Beckman Coulter ${ }^{\circ}$, Avanti J-26 XPI centrifuge) (22). Six millilitres (6 ml) of the supernatant were transferred into a roQ QuEChERS 15 $\mathrm{ml}$ centrifuge tube (KSO-9507) containing $900 \mathrm{mg} \mathrm{\textrm {MSO } _ { 4 }}$ and $150 \mathrm{mg}$ primary secondary amine (PSA) (22). The tube was shaken by hand for 30 secs and then centrifuged as above (22). Thereafter, $1 \mathrm{ml}$ of the supernatant was filtered through a $0.45 \otimes \mathrm{m}$ pore filter and transferred into a $1.5 \mathrm{ml}$ autosampler vial (all purchased from Separations (Pvt) Ltd, Johannesburg, RSA) (22). This was repeated for all the samples and the vials were left open in a laminar flow cabinet overnight to dry (22).

The samples were analysed for the quantification of DON and ZEA using high performance liquid chromatography (HPLC). The HPLC system consisted of an LC-2030 pump connected to an LC-2030/2040 PDA detector, LC-2030 controller and LC-2030 autosampler. Chromatographic separations were performed on a Kinetex 5 m Biphenyl 100A LC Column $(100 \times 2.1 \mathrm{~mm})$ connected to a guard column SecurityGuard $^{\mathrm{TM}}$ filled with the same phase (2.1 to $4.6 \mathrm{~mm}$ ) (all purchased from Separations (Pvt) Ltd, Johannesburg, RSA). The mobile phase consisted of aqueous $5 \mathrm{mM}$ ammonium acetate with $0.1 \%$ acetic acid, $5 \mathrm{mM}$ ammonium acetate in methanol with $0.1 \%$ acetic acid, acetonitrile and Milli-Q water. The flow rate was $0.20 \mathrm{~mL} / \mathrm{min}$ and the injection volume was 50l. The retention times for DON and ZEA were 2.563 and 10.193 mins respectively. Quantification was relative to external standards of $1-8 \mathrm{~g} / \mathrm{mL}$ in acetonitrile. Three quantification readings were conducted per sample.

\section{Data analysis}

A general linear model (GLM) was used to run an Analysis of Variance (ANOVA) on the percentage inhibition data from the primary and secondary screening experiments. Disease severity data was used to calculate the Area Under the Disease Progress Curve (AUDPC) for all treatments (23) before subjected to ANOVA. If the ANOVA was significant $(P \leq 0.05)$, the means were separated using the Duncan's multiple range test (DMRT) at 5\% significance level using SAS software Version 9.4 (24).

HSW, PSI and disease severity data were checked for homogeneity within the repeated trials and were then pooled according to treatments. Thereafter, an ANOVA was conducted on the pooled data and the treatment means were separated using the DMRT at a 5\% significance level. Pairwise correlations were determined between AUDPC, HSW and PSI for the pooled data using the Spearman's correlation test. The rate of disease progress $(r)$ was calculated using the Vanderplanks' logistic equation (25) expressed below:

$$
r=\frac{1}{t_{2}-t_{1}}\left[\left(\ln \frac{x_{2}}{1-x_{2}}\right)-\left(\ln \frac{x_{1}}{1-x_{1}}\right)\right]
$$

where; $t_{1}$ - initial day of rating

$t_{2}$ - final day of rating

$x_{1}$-initial disease value

$\mathrm{x}_{2}$ - final disease value

\section{Results}

Evaluation of ASM applications and application times

Differences in disease severity levels amongst the treat-

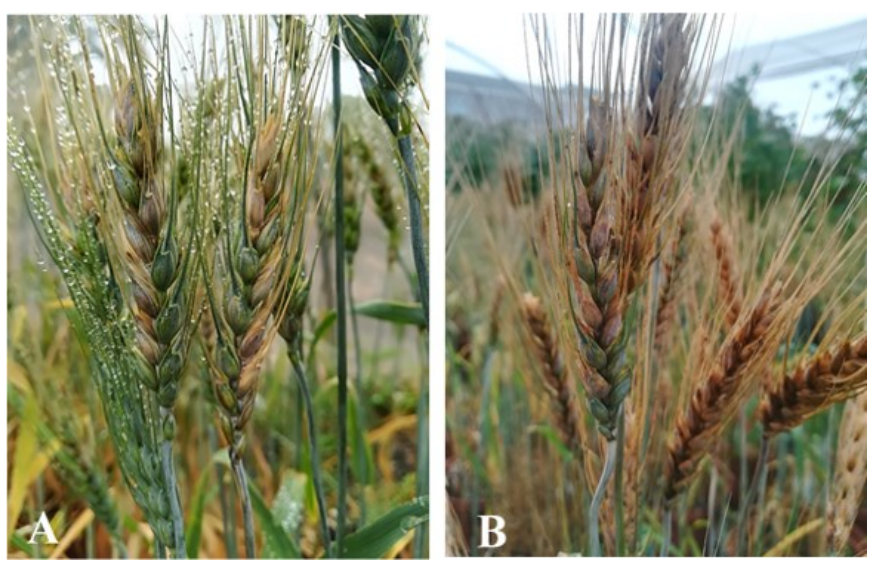

Fig. 1. Visual differences in disease severity levels between two treatments at $16 \mathrm{dpi}$; (A) ASM at $0.019 \mathrm{~g} / \mathrm{L}$ ASM applied at late boot stage compared to (B) control treatment with no ASM application

ments were observed (Fig. 1 and Fig. 2). For example, at 16 days post inoculation (dpi), the ASM treatment $0.019 \mathrm{~g} / \mathrm{L}$ ASM applied at late boot had an average disease severity of $40.17 \%$ whereas the control had an average disease severity of $70.00 \%$ (Fig. 1). The control (0 g/L ASM at anthesis) had the highest disease severity in all rating days during the trial (Fig. 2) with the final disease severity of $88.46 \%$, thus the highest AUDPC, lowest average HSW and highest average PSI.

Higher ASM concentrations were more effective when applied at anthesis and lower concentrations at late boot (Table 2). Moreover, repeated applications (applied at both late boot and anthesis) did not improve disease reduction. These were not significantly different at $p<0.05$. Differences between ASM concentrations were not significant for the AUDPC and HSW but significantly different ( $p=$ 0.003) for the PSI (Table 2). However, differences between growth stages were significant at $p<0.05$ for all three parameters measured (Table 2 ).

The best treatment, providing the lowest AUDPC units, high average HSW and reduced average PSI was 0.075 $\mathrm{g} / \mathrm{L}$ ASM applied at anthesis. Following this were treatments $0.019 \mathrm{~g} / \mathrm{L} \mathrm{ASM}$ at late boot and $0.0563 \mathrm{~g} / \mathrm{L} \mathrm{ASM}$ at anthesis respectively, providing effective disease reduction and high average HSW (Table 2). The calculated rate of disease progress $(r)$ varied across all the ASM treatments and the control (Table 2). The interaction between the ASM concentrations and the growth stages were significant for all three parameters measured (Table 2).

\section{Correlation analysis}

Pairwise correlations between AUDPC, HSW and PSI are presented in Table 3. Significant correlations were observed for all the pairwise combinations. A week positive correlation was observed between AUDPC and PSI ( $r=0.33$; $p=0.0001$ ). However, a moderate and very week negative correlation was observed between AUDPC and HSW ( $r=$ $0.41 ; p<0.0001)$ and HSW and PSI $(r=-0.18 ; p=0.04)$ re- 
Table 2. The Area Under the Disease Progress Curve (AUDPC), average Hundred Seed Weight (HSW) (g), average Percentage Seed Infection (PSI) (\%) and rate of disease progress ( $r$ ) for the 12 acibenzolar-S-methyl (ASM) treatments and Control tested against Fusarium head blight (FHB) of wheat.

\begin{tabular}{|c|c|c|c|c|c|}
\hline ASM Concentrations $\left(\mathrm{g} \mathrm{L}^{-1}\right)$ & Growth Stage(s) & AUDPC Units & Average HSW (g) & Average PSI (g) & (r) \\
\hline 0.019 & Anthesis & $460.31 \pm 42.2^{\mathrm{bc}}$ & $2.12 \pm 0.17^{\mathrm{bcd}}$ & $69.00 \pm 4.26^{\mathrm{cd}}$ & 0.20 \\
\hline 0.019 & Late boot & $348.65 \pm 47.47^{c}$ & $2.42 \pm 2.0 .07^{\mathrm{abc}}$ & $65.67 \pm 8.34^{\mathrm{cd}}$ & 0.22 \\
\hline 0.019 & Anthesis and Late boot & $412.61 \pm 20.28^{\mathrm{bc}}$ & $2.12 \pm 0.11^{\mathrm{abcd}}$ & $62.00 \pm 3.83^{\mathrm{cd}}$ & 0.18 \\
\hline 0.0375 & Anthesis & $509.38 \pm 41.29^{b}$ & $2.55 \pm 0.10^{\mathrm{a}}$ & $66.00 \pm 4.38^{\mathrm{cd}}$ & 0.21 \\
\hline 0.0375 & Late boot & $364.65 \pm 33.41^{c}$ & $2.06 \pm 0.17^{\mathrm{cd}}$ & $67.89 \pm 4.70^{c d}$ & 0.21 \\
\hline 0.0563 & Anthesis & $375.44 \pm 38.62^{c}$ & $2.35 \pm 0.17^{\mathrm{abc}}$ & $59.44 \pm 5.31^{d}$ & 0.28 \\
\hline 0.0563 & Late boot & $404.60 \pm 19.73^{b c}$ & $2.22 \pm 0.07^{\mathrm{abcd}}$ & $74.67 \pm 3.13^{b c}$ & 0.24 \\
\hline 0.0563 & Anthesis and Late boot & $457.20 \pm 30.42^{\mathrm{bc}}$ & $1.94 \pm 0.08^{\mathrm{d}}$ & $89.78 \pm 1.89^{a}$ & 0.20 \\
\hline 0.075 & Anthesis & $340.54 \pm 47.71^{c}$ & $2.46 \pm 0.13^{\mathrm{ab}}$ & $68.81 \pm 4.48^{\mathrm{cd}}$ & 0.22 \\
\hline 0.075 & Late boot & $438.12 \pm 22.06^{\mathrm{bc}}$ & $2.56 \pm 0.08^{\mathrm{abc}}$ & $84.00 \pm 2.71^{\mathrm{ab}}$ & 0.21 \\
\hline 0.075 & Anthesis and Late boot & $627.83 \pm 41.65^{\mathrm{a}}$ & $2.09 \pm 0.11^{\mathrm{bcd}}$ & $72.11 \pm 4.58^{\mathrm{bcd}}$ & 0.17 \\
\hline 0 (Control) & Anthesis & $718.14 \pm 34.43^{\mathrm{a}}$ & $1.93 \pm 0.03^{d}$ & $93.67 \pm 1.40^{\mathrm{a}}$ & 0.22 \\
\hline \multicolumn{6}{|l|}{ Effects } \\
\hline \multirow[t]{2}{*}{ ASM Concentrations } & F value & 1.86 & 0.82 & 2.99 & \\
\hline & $P$ value & 0.14 & 0.49 & 0.03 & \\
\hline \multirow[t]{2}{*}{ Growth Stages } & F value & 6.57 & 3.98 & 4.47 & \\
\hline & $P$ value & 0.002 & 0.02 & 0.01 & \\
\hline \multirow[t]{2}{*}{ ASM Concentrations ${ }^{\star}$ Growth Stages } & F value & 5.44 & 2.30 & 3.95 & \\
\hline & $P$ value & $<0.0001$ & 0.03 & 0.001 & \\
\hline$\% \mathrm{CV}$ & & 27.61 & 17.38 & 19.94 & \\
\hline
\end{tabular}

Values followed by the same superscript letter are statistically identical according to the Duncan's Multiple Range Test (DMRT) at a 5\% significance level

Table 3. Pairwise correlation between the Area Under the Disease Progress Curve (AUDPC), Hundred Seed Weight (HSW) and Percentage Seed Infection (PSI) for the different acibenzolar-S-methyl (ASM) treatments against Fusarium head blight (FHB).

\begin{tabular}{lccc}
\hline & AUDPC & HSW & \multicolumn{1}{c}{ PSI } \\
\hline AUDPC & 1.00 & $-0.41^{\star}$ & $0.33^{\star \star}$ \\
HSW & & 1.00 & $-0.18^{\star \star \star}$ \\
PSI & & & 1.00 \\
\hline
\end{tabular}

Key: $\left({ }^{\star}\right)=$ significant at $p<0.0001 ;\left(^{\star \star}\right)=$ significant at $p=0.0001 ;\left(^{\star \star \star}\right)=$ significant at $p=0.0445$

spectively. The highest negative correlation observed was between AUDPC and HSW.

\section{Mycotoxin analysis}

DON concentrations ranged from 13.45-19.45 ppm whereby the control had a DON concentration of $16.56 \mathrm{ppm}$ (Table
4). On the other hand, ZEA concentrations ranged from 1.92 -9.48 ppm whereby the control had the third lowest ZEA concentration (2.98 ppm) (Table 4). Three treatments, namely $0.019 \mathrm{~g} / \mathrm{L} \mathrm{ASM}$ at late boot stage, $0.0563 \mathrm{~g} / \mathrm{L} \mathrm{ASM}$ at anthesis and $0.075 \mathrm{~g} / \mathrm{L} \mathrm{ASM}$ at late boot stage, did not reduce DON concentration when compared to the control. However, only two treatments, namely $0.019 \mathrm{~g} / \mathrm{L} \mathrm{ASM} \mathrm{at}$ late boot stage and $0.0563 \mathrm{~g} / \mathrm{L} \mathrm{ASM}$ at anthesis, reduced ZEA concentration in harvested grain.

\section{Discussion}

ASM is a plant resistance activator that has been used in many plants to incite resistance against various pathogens (18). ASM is translocated systemically in plants and follows

Table 4. Concentrations of deoxynivalenol (DON) and zearalenone (ZEA) in harvested grains for the 12 treatments and the control. Percentage reduction is in comparison with the Control treatment

\begin{tabular}{|c|c|c|c|c|}
\hline \multirow{2}{*}{ Treatment } & \multicolumn{2}{|c|}{ DON } & \multicolumn{2}{|r|}{ ZEA } \\
\hline & Concentration (ppm) & Percentage reduction (\%) & Concentration (ppm) & Percentage reduction (\%) \\
\hline $0.019 \mathrm{gL}^{-1} \mathrm{ASM}$ at anthesis & $13.57^{\mathrm{bc}}$ & 18.09 & $5.59^{\text {abcdef }}$ & * \\
\hline $0.019 \mathrm{gL}^{-1} \mathrm{ASM}$ at late boot stage & $19.45^{\mathrm{a}}$ & * & $2.39^{\mathrm{ef}}$ & 19.83 \\
\hline $0.019 \mathrm{gL}^{-1} \mathrm{ASM}$ at late boot stage and anthesis & $16.52^{\mathrm{abc}}$ & 0.25 & $7.90^{\mathrm{abc}}$ & * \\
\hline $0.0375 \mathrm{gL}^{-1} \mathrm{ASM}$ at anthesis & $13.45^{\mathrm{c}}$ & 18.79 & $9.48^{\mathrm{a}}$ & * \\
\hline $0.0375 \mathrm{gL}^{-1} \mathrm{ASM}$ at late boot stage & $15.04^{\mathrm{bc}}$ & 9.18 & $4.60^{\text {bcdef }}$ & * \\
\hline $0.0375 \mathrm{gL}^{-1} \mathrm{ASM}$ at late boot stage and anthesis & $16.53^{\mathrm{abc}}$ & 0.19 & $3.77^{\text {cdef }}$ & * \\
\hline $0.0563 \mathrm{gL}^{-1} \mathrm{ASM}$ at anthesis & $17.00^{\mathrm{ab}}$ & * & $1.92^{f}$ & 35.79 \\
\hline $0.563 \mathrm{gL}^{-1} \mathrm{ASM}$ at late boot stage & $14.50^{\mathrm{bc}}$ & 12.46 & $6.78^{\text {abcde }}$ & * \\
\hline $0.0563 \mathrm{gL}^{-1} \mathrm{ASM}$ at late boot stage and anthesis & $16.42^{\mathrm{abc}}$ & 0.88 & $7.63^{\mathrm{abcd}}$ & * \\
\hline $0.075 \mathrm{gL}^{-1} \mathrm{ASM}$ at anthesis & $14.33^{\mathrm{bc}}$ & 13.47 & $8.87^{\mathrm{ab}}$ & * \\
\hline $0.075 \mathrm{gL}^{-1} \mathrm{ASM}$ at late boot stage & $16.60^{\mathrm{abc}}$ & * & $4.73^{\text {bcdef }}$ & * \\
\hline $0.075 \mathrm{gL}^{-1} \mathrm{ASM}$ at late boot stage and anthesis & $14.90^{\mathrm{bc}}$ & 10.02 & $6.29^{\text {abcdef }}$ & * \\
\hline
\end{tabular}




\begin{tabular}{|c|c|c|c|c|}
\hline Control & $16.56^{\mathrm{abc}}$ & 0.00 & $2.98^{\mathrm{def}}$ & 0.00 \\
\hline$F$ value & 2.66 & & 3.06 & \\
\hline$P$ value & 0.02 & & 0.0082 & \\
\hline \%C.V. & 11.19 & & 43.49 & \\
\hline
\end{tabular}

a SA signalling pathway thus inducing SAR (18). Most ASM treatment concentrations used were able to reduce the disease severity compared to the control.

The disease severity for all the treatments increased steadily throughout the duration of the trials where the control had the highest disease severity in all rating days. According to the calculated AUDPC, the best ASM treatment was $0.075 \mathrm{~g} / \mathrm{L}$ ASM at anthesis. A disease reduction of up to $28.97 \%$ compared to the control was achieved by using this ASM concentration, thus indicating that the application of ASM can reduce FHB severity. This treatment $(0.075 \mathrm{~g} / \mathrm{L}$ ASM at anthesis) also had the highest average percentage reduction in AUDPC units (52.60\%) compared to the control. This is also the recommended ASM concentration $(0.075 \mathrm{~g} / \mathrm{L})$ for applications on tomato plants.

As a result of FHB infection, Fusarium-damaged kernels (FDKs) are produced which have a shrivelled and discoloured appearance and are fairly light-weight (26). This leads to yield and quality losses as these grains can no longer be used as either food, feed or seed $(5,9)$. A thirdhighest average HSW was obtained for the best ASM treatment $(0.075 \mathrm{~g} / \mathrm{L} \mathrm{ASM}$ at anthesis) as well as the sixth lowest average PSI. This suggests that apart from reducing disease severity, ASM application improved crop yield by reducing the number of FDKs. This also agrees with the pairwise correlation analysis conducted in this study which revealed that HSW had a negative correlation with AUDPC and PSI, whereas a positive correlation was observed between the AUDPC and PSI. In this study, the best treatment was expected to have the lowest PSI. However, this was not the case. This could be attributable to latent infections or postharvest disease spread which could lead to an increase in PSI.

The higher ASM concentrations $(0.075 \mathrm{~g} / \mathrm{L}$ and 0.0563 $\mathrm{g} / \mathrm{L}$ ) were more effective when applied at anthesis whereas the lower ASM concentrations $(0.0375 \mathrm{~g} / \mathrm{L}$ and $0.019 \mathrm{~g} / \mathrm{L})$ were more effective when applied at the late boot stage. Disease protection usually begins between 4 to 6 days after ASM application on tomatoes (27). Therefore, it was expected that earlier application [at late boot (14 days before anthesis in this study)] would provide more disease reduction. For the higher ASM concentrations to effectively reduce disease severity when applied 48 hrs before $F$. graminaearum, there could be a possible immediate or faster induction of basal resistance by SAR.

Wheat spikes inoculated with only F. graminearum triggered SA signalling after $12 \mathrm{hrs}$ of pathogen inoculation (14). It was concluded that SA signalling could be responsible for basal resistance against $F$. graminearum in wheat (14). Therefore, it is possible that higher ASM concentrations lead to faster accumulation of the elicitor in the plant and thus primes the plants for disease resistance faster than at lower concentrations. This could mean that at lower ASM concentrations, more time is required for the uptake and accumulation of the elicitor which could result in the slow translocation of the elicitor throughout the plant and thus delayed resistance priming of the plants against FHB infection.

Sodium salt of salicylic acid (NaSA) and isonicotinic acid (INA), were reported to significantly reduce FHB severity compared to the untreated control when sprayed three days prior to inoculation with Gibberella zeae (28). These inducers as well as $\beta$-amino- $n$-butyric acid (BABA), significantly reduced FHB severity when low concentrations (1 $\mathrm{mM}$ ) were applied 10 days prior to pathogen inoculation. This is in alignment with the performance of ASM treatments reported in the present study where lower concentrations were more effective when applied at late boot stage and higher concentration at anthesis ( $48 \mathrm{hrs}$ prior to pathogen inoculation). However, in another study there was no significant effect on 100-kernel weight associated with the application of resistance inducers (28).

A more enhanced disease reduction was expected in treatments where ASM concentrations were applied twice (at the late boot stage and at anthesis) (repeated application treatments) due to the increased frequency of ASM applications (27). However, the repeated application treatments for the higher concentrations $(0.075 \mathrm{~g} / \mathrm{L}$ and 0.0563 $\mathrm{g} / \mathrm{L}$ ) had higher AUDPC values compared to their single applications. It is possible that the increased frequency of ASM applications resulted in increased plant stress thus making the plants more susceptible to infection instead of priming them for resistance as expected. Moreover, ASM applications in the repeated application treatments were within the recommended application interval times (not less than 7 days) for tomato plants set by Syngenta (information found on the product label of ASM). Therefore, the application of higher ASM concentrations twice in 14 days could have led to plant toxicity thus encouraging FHB disease development. Moreover, in a study where ASM concentrations at various application intervals were tested against Bacterial spot in tomato plants, the ideal application intervals were 8 and 10 days (27).

At lower ASM concentrations $(0.0375 \mathrm{~g} / \mathrm{L}$ and $0.019 \mathrm{~g} /$ L), the repeated application treatments had AUDPC values higher than those of late boot applications but lower than those of anthesis applications. Although they were more effective than anthesis applications, repeated application treatments did not improve disease reduction. Nonetheless, the repeated application treatments for the lower ASM concentrations were more effective compared to those of the higher concentrations.

From the mycotoxin analysis, most ASM treatments were able to reduce DON concentrations whereby the best DON reduction was by the treatment $0.0375 \mathrm{~g} / \mathrm{L} \mathrm{ASM}$ at anthesis $(18.79 \%)$. This treatment had one of the highest AUDPC values and interestingly a high HSW and low PSI. According to literature, a reduction in disease severity most 
likely results in DON reduction and high seed weight $(1,5$, 9). Therefore, treatments with high AUDPC values were expected to have low HSW and high PSI but this was not the case.

Three treatments had DON concentrations higher than that of the control. These include $0.019 \mathrm{~g} / \mathrm{L} \mathrm{ASM}$ at late boot stage, $0.0563 \mathrm{~g} / \mathrm{L} \mathrm{ASM}$ at anthesis and $0.075 \mathrm{~g} / \mathrm{L} \mathrm{ASM}$ at late boot stage. Two of these treatments, namely $0.019 \mathrm{~g} / \mathrm{L}$ ASM at late boot stage and $0.0563 \mathrm{~g} / \mathrm{L} \mathrm{ASM}$ at anthesis, were the only treatments that reduced ZEA concentration (19.83\% and $35.79 \%$, respectively). However, most treatments had ZEA concentration higher than that of the control. Therefore, there was no apparent correlation between ZEA concentrations and other tested parameters in this study.

Research with ASM treatments on crops such as Cice arietinum $\mathrm{L}$. led to increased accumulations of polyphenols and anti-oxidants. These include ascorbate and glutathione, which could protect cells during stress events and improve tolerance to pathogens attack $(29,30)$. In response to ASM treatments, metabolomic studies have also identified changes in amino acids, organic acids and sugar accumulations which include glucose, malic acid and sucrose (31). Reactive oxygen species (ROS) are essential second messengers in stomatal-based defence (32). Application of ASM on Japanese radish resulted in induced stomatal closure by inducing ROS production through peroxidase. The stomatal closure induced by the ASM treatment was effective in preventing invasion of Japanese radish by Pseudomonas cannabina pv. alisalensis.

In the present study, the relationship between AUDPC and mycotoxin (DON and ZEA) reduction was inconsistent. However, to the best of our knowledge, this is the first report of ASM being tested against FHB and mycotoxin reduction caused by $F$. graminearum on wheat. This study reveals the potential of ASM applications as an effective control strategy of FHB. Although ASM was effective in reducing FHB severity on wheat plants, further research is required to better understand the effect of ASM on mycotoxin concentrations in grains.

\section{Conclusion}

The application of ASM at small doses effectively reduced FHB disease severity and provided inconsistent DON reduction. Regardless of the observed efficacy, the integration of ASM with other effective control strategies could further provide enhanced FHB reduction. Moreover, field trials to test the spectrum of activity of ASM in various environments or in environments similar to those present in wheat commercial cultivation areas is crucial.

\section{Acknowledgements}

This study was funded by the University of KwaZulu-Natal Capacity Development Programme (UCDP), South Africa. The authors are also grateful to the National Research Foundation (NRF) of South Africa for student bursary.

\section{Authors contributions}

SPNS carried out the work and wrote the initial draft of the manuscript, implemented the comments after editing and revised the manuscript. NCM student co-supervision, funding acquisition and proof-reading of the final draft. KSY student supervision, project leadership and management, funding acquisition and editing of manuscript.

\section{Compliance with ethical standards}

Conflict of interest: The authors declare that they have no competing interests.

Ethical issues: None.

\section{References}

1. Dweba CC, Figlan S, Shimelis HA, Motaung TE, Sydenham S, Mwadzingeni L, Tsilo TJ. Fusarium head blight of wheat: Pathogenesis and control strategies. Crop Prot. 2017;91:114-22. https://doi.org/10.1016/j.cropro.2016.10.002

2. Yang F, Jacobsen S, Jorgensen HJL, Collinge DB, Svensson B, Finnie C. Fusarium graminearum and its interactions with cereal heads: studies in the proteomics era. Front. Plant Sci. 2013;4 (37):1-8. https://doi.org/10.3389/fpls.2013.00037

3. Boutigny AL, Beukes I, Viljoen A. Head blight of barley in South Africa is caused by Fusarium graminearum with a 15-adon chemotype. J. Plant Pathol. 2011;93:321-29. https:// doi.org/10.4454/JPP.V93I2.1186

4. Muthomi JW, Ndung'u JK, Gathumbi JK, Mutitu EW, Wagacha JM. The occurrence of Fusarium species and mycotoxins in Kenyan wheat. Crop Prot. 2008;27:1215-19. https://doi.org/10.1016/ j.cropro.2008.03.001

5. Schoeman A, Greyling-Joubert SM. Gibberella on maize, sorghum and wheat. Grain SA. [Internet] 2017. [Cited 2017 Jul 7]. Available from: https://www.grainsa.co.za/gibberella-on-maize,-sorghumand-wheat.

6. Gilbert J, Haber S. Overview of some recent research developments in Fusarium head blight of wheat. Can J Plant Pathol. 2013;35:149-74. https://doi.org/10.1080/07060661.2013.772921

7. Jouany JP. Methods for preventing, decontaminating and minimizing the toxicity of mycotoxins in feeds. Anim Feed Sci Technol.2007;137:342-62. j.anifeedsci.2007.06.009

https://doi.org/10.1016/

8. Salgado JD, Wallhead M, Madden LV, Paul PA. Grain harvesting strategies to minimize grain quality losses due to Fusarium head blight in wheat. Plant Dis. 2011;95:1448-57. https:// doi.org/10.1094/PDIS-04-11-0309

9. Wegulo SN, Baenziger PS, Nopsa JH, Bockus WW, Hallen-Adams $\mathrm{H}$. Management of Fusarium head blight of wheat and barley. Crop Prot. 2015;73:100-07. https://doi.org/10.1016/ j.cropro.2015.02.025

10. Makandar R, Nalam VJ, Lee H, Trick HN, Dong Y, Shah J. Salicylic acid regulates basal resistance to Fusarium head blight in wheat. Mol. Plant Microbe Interact. 2012;25:431-39. https:// doi.org/10.1094/MPMI-09-11-0232

11. Rios JA, Rodrigues FA, Debona D, Resende RS, Moreira WR, Andrade CCL. 2014. Induction of resistance to Pyricularia oryzae in wheat by acibenzolar-S-methyl, ethylene and jasmonic acid. Trop Plant Pathol. 2014;39(3):224-33. https://doi.org/10.1590/ S1982-56762014000300006

12. Jia H, Zhou J, Xue S, Li G, Yan H, Ran C, Zhang Y, Shi J, Jia L, Wang $\mathrm{X}$, Luo J, Ma Z. A journey to understand wheat Fusarium head 
blight resistance in the Chinese wheat landrace Wangshuibai. Crop J. 2-17;6:48-59. https://doi.org/10.1016/j.cj.2017.09.006

13. Walter S, Nicholson P, Doohan FM. Action and reaction of host and pathogen during Fusarium head blight disease. New Phytol. 2010;185:54-66.https://doi.org/10.1111/j.1469-8137.2009.03041.x

14. Palazzini J, Roncallo P, Cantoro R, Chiotta M, Yerkovich N, Palaciois S, Echenique V, Torres A, Ramirez M, Karlovsky P, Chulze S. 2018. Biocontrol of Fusarium graminearum sensu stricto, reduction of deoxynivalenol accumulation and phytohormone induction by two selected antagonists. Toxins. 2018;10:88 (2). https://doi.org/10.3390/toxins10020088

15. Görlach J, Volrath S, Knauf-Beiter G, Hengy G, Beckshove U, Kogal KH, Oosterndorp M, Staub T, Ward E, Kessmann H, Ryals J. Benzothiadiazole, a novel class of inducers of systemic acquired resistance in wheat. Plant Cell. 1996;8:629-43. https:// doi.org/10.1105/tpc.8.4.629

16. Makandar R, Essig JS, Schapaugh MA, Trick HN, Shah J. Genetically engineered resistance to Fusarium head blight in wheat by expression of Arabidopsis NPR1. Mol. Plant Microbe Interact. 2006;19(2):123-29. https://doi.org/10.1094/MPMI-19-0123.

17. Ding L, Xu H, Yi H, Yang L, Kong Z, Zhang L, Xue S, Jia H, and Ma Z. Resistance to hemi-biotrophic $F$. graminearum infection is associated with coordinated and ordered expression of diverse defence signalling pathways. PLoS One. 2011;6:e19008. Published online. https://doi.org/10.1371/journal.pone.0019008.

18. Oostendorp M, Kunz W, Dietrich B, Staub T. Induced disease resistance in plants by chemicals. Eur J Plant Pathol. 2001;107:928. https://doi.org/10.1023/A:1008760518772

19. Santos HAA, Pria MD, Silva OC, De Mio MLL. Control of wheat diseases using phosphites and acibenzolar-S-methyl alone or associated with piraclostrobina + epoxiconazole. Semin-Cienc. Agrar. 2011;32(2):433-42. https://doi.org/10.5433/16790359.2011v32n2p433

20. Lancashire PD, Bleiholder $\mathrm{H}$, Van den Boom $\mathrm{T}$, Langelüddeke $\mathrm{P}$, Stauss R, Weber E, Witzenberger A. A uniform decimal code for growth stages of crops and weeds. Ann Appl Biol. 2008;119:561601. https://doi.org/10.1111/j.1744-7348.1991.tb04895.x

21. Engle JS, Lipps PE, Mills D. Fusarium head blight severity scale for winter wheat. Bulletin AC-48-03, 2003. Extension Factsheet, Ohio State University.

22. Trass M, Misa A, Rivers B. A rapid extraction and screening method for mycotoxins from cereal products using QuEChERS and LC/ MS/MS. Phenomenex Technical Note (TN0071). [Internet] 2019 [Cited 30 June 2019]. Available from: https://phenomenex.com

23. Shaner G, Finney RE. The effect of nitrogen fertilization on the expression of slow-mildewing resistance in Knox wheat. Phytopathology. 1977;67:1051-56. https://doi.org/10.1094/PHYTO-671051
24. SAS Institute Inc. SAS 9.4 System Operations: Reference, Fifth Edition. Cary, NC: SAS Institute Inc. [Internet] 2016 [4 Aug 2019] Available from: https://citeseerx.ist.psu.edu/viewdoc/download? doi=10.1.1.353.6870\&rep=rep1\&type=pdf

25. Van der Plank JE. Plant diseases: Epidemics and control. New York: Academic Press; 1963. https://doi.org/10.1097/00010694196410000-00018.

26. McMullen M, Bergstrom G, De Wolf E, Dill-Macky R, Hershman D, Shaner G, Van Sanford D. 2012. A united effort to fight an enemy of wheat and barley: Fusarium head blight. Plant Dis. 2012;96 (12):1712-28. https://doi.org/10.1094/PDIS-03-12-0291-FE

27. Pontes $\mathrm{N}$ de $\mathrm{C}$, Nascimento A dos R, Golynski A, Maffia LA, de Oliveira JR, Quezado-Duval AM. Intervals and number of applications of Acibenzolar-S-Methyl for the control of bacterial spot on processing tomato. APS Publ. 2016,100(10):2126-33. https:// doi.org/10.1094/PDIS-11-15-1286-RE

28. Zhang S, Schisler DA, Boehm MJ, Slininger PJ. Utilization of chemical inducers of resistance and Cryptococcus flavescens $\mathrm{OH}$ 182.9 to reduce Fusarium head blight under greenhouse conditions. Biol Control. 2007;42:308-15. https://doi.org/10.1016/ j.biocontrol.2007.05.020

29. Kuźniak E, Głowacki R, Chwatko G, Kopczewski T, Wielanek M, Gajewska E. Involvement of ascorbate, glutathione, protein Sthiolation and salicylic acid in benzothiadiazole-inducible defence response of cucumber against Pseudomonas syringae $p v$ lachrymans. Physiol Mol Plant Pathol. 2014;86:89-97. https:// doi.org/10.1016/j.pmpp.2014.04.004

30. Meher HC, Gajbhiye V T, Singh G, Chawla G. Altered metabolomic profile of selected metabolites and improved resistance of Cicer arietinum (L.) against Meloidogyne incognita (Kofoid \& White) Chitwood following seed soaking with salicylic acid, benzothiadiazole or nicotinic acid. Acta Physiol. Plant. 2015; 37:140. https:// doi.org/10.1007/s11738-015-1888-6

31. Baldoni E, Mattana M, Locatelli F, Consonni R, Cagliani LR, Picchi V. Analysis of transcript and metabolite levels in Italian rice (Oryza sativa L.) cultivars subjected to osmotic stress or benzothiadiazole treatment. Plant Physiol Biochem. 2013;70:492-503. https://doi.org/10.1016/j.plaphy.2013.06.016

32. Sakata N, Ishiga T, Taniguchi S, Ishiga Y. Acibenzolar-S-methyl activates stomatal-based defense systemically in Japanese Radish. Front Plant Sci. 2020;11:1670. https://doi.org/10.3389/ fpls.2020.565745 